\section{The role of amorphous P-bearing precursors on barite formation}

\section{Ruiz-Agudo ${ }^{1 *}$, A. Ibáñez-Velasco², E. Ruiz-Agudo²}

Abstract

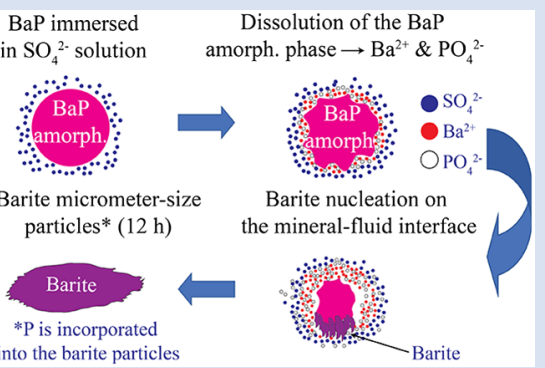
into the barite particles
Past climate variations on Earth are recorded in sedimentary rocks by chemical and biological indicators. In this sense, investigations of sedimentary marine barites $\left(\mathrm{BaSO}_{4}\right)$ have been fundamental to reconstruct geochemical evolution of palaeoenvironments. Despite the significant advances achieved during the past decade, the mechanism of barite formation in the ocean water column in undersaturated conditions and the role of microorganisms remain controversial. Phosphorus-rich, amorphous precursor phases have been suggested to play a key role, although the exact mechanism of marine barite formation from this precursor is not well constrained. In this paper, we evidence that barite can precipitate by replacing amorphous Ba-P precursor phases formed in the absence of living organisms. This occurs by a mineral replacement reaction, yielding an abiotic scenario for barite particles with morphologies, mesostructure and composition resembling barite formed in the marine water column. This demonstrates the need to investigate how this formation process, via the replacement of an amorphous precursor, affects the isotopic and trace element signatures of barite, and how this influences the environmental information obtained from this proxy.

\section{Introduction}

Oceanic minerals buried in sedimentary rocks record palaeoenvironmental changes through their chemical and isotopic composition. A prominent example is marine barite $\left(\mathrm{BaSO}_{4}\right)$ which is widely used to provide palaeoceanographic and palaeoclimatic information due its resilient character (Griffith and Paytan, 2012). The geochemical composition of the fluid from which barite precipitated can be inferred from the trace element and isotopic content of the $\mathrm{BaSO}_{4}$ particles. Furthermore, the accumulation of barite in geological records stands as a common proxy for the reconstruction of the marine carbon cycle (Paytan et al., 1996; Paytan and Griffith, 2007) and global climate (Martinez-Ruiz et al., 2015). It is commonly observed that barite in sediments is concentrated beneath regions of high biological productivity (Kastner, 1999).

Interestingly, the ocean is generally undersaturated with respect to barite (with only few exceptions; Monnin et al., 1999), which has fostered a strong debate on the mechanism underlying barite precipitation in the water column during the last decades, since it could impact the validity of marine barite as a palaeoproxy (Paytan et al., 1996). Because of the link between the abundance of bacteria and barite (Dehairs et al., 2008; Jacquet et al., 2011; Planchon et al., 2013), several studies have focused on the role of bacteria on barite formation. In sulfate-rich environments, such as seawater, the bioaccumulation of barium on the extracellular polymeric substances (EPS) produced by bacteria has been suggested to be key to the precipitation of barite from undersaturated seawater (GonzalezMuñoz et al., 2012; Martinez-Ruiz et al., 2018, 2019). These authors showed that in both laboratory experiments and natural environments, barite crystallisation is preceded by the accumulation of barium on EPS, followed by the formation of an amorphous phosphorus-rich phase and its subsequent transformation into barite crystals. Despite these recent advances in our understanding of barite formation in marine environments, aspects such as the exact accumulation mechanism of barium by bacteria, the characteristics of the transient amorphous P-rich phase and the mechanism of its transformation into barite are not yet fully understood. This is a crucial step to better characterise marine productivity using this proxy, a key parameter in the global carbon cycle.

Since organic matter is the main source of most $\mathrm{P}$ in marine environments (Schoepfer et al., 2015), concentration of P compounds in seawater and biological activity are strongly correlated. Indeed, organic phosphorus is a commonly used proxy for marine productivity (Schoepfer et al., 2015). P esters and phosphonates are the principal compounds included in the high molecular weight dissolved organic phosphorus (DOP; the major fraction of the soluble nonreactive phosphorus) fraction in the water column, which represents approximately a quarter of total DOP in the upper ocean (Paytan and McLaughlin, 2007). Herein, we selected phytic acid, a sixfold dihydrogenphosphate ester of inositol as a model since it is a relatively simple organic phosphate compound containing a large number of the characteristic phosphoester (C-O-P) bonds of high molecular weight

1. Department of Physical Chemistry, University of Konstanz, 78457 Konstanz, Germany

2. Department of Mineralogy and Petrology, University of Granada, Fuentenueva s/n, 18071 Granada, Spain

Corresponding author (email: cristina.ruiz-agudo@uni-konstanz.de) 
DOP compounds in the water column. Our aim was to investigate the role that these compounds may have in the formation of barite. Note that EPS, which has been shown to be relevant in the precipitation of barite in marine environments, are natural polymers of high molecular weight secreted by microorganisms, such as those present in the high molecular weight DOP fraction of the water column. Additional experiments were performed using an inorganic P source with the objective of determining if a purely inorganic $P$ phase could have similar effects on barite formation and the resultant crystal morphologies. We demonstrate that barite crystals with similar morphologies and sizes as marine barite found in seawater and marine sediments (Dehairs et al.,1980; Griffith and Paytan, 2012) can precipitate in an abiotic process through the replacement of amorphous $\mathrm{Ba}-\mathrm{P}$ phases obtained from both organic and inorganic P compounds in a sulfate-bearing media.

\section{Materials and Methods}

Synthesis of the barite precipitates. In a first set of experiments, precipitation of barite was achieved by slow titration of $\mathrm{Na}_{2} \mathrm{SO}_{4}$ $(1 \mathrm{mM})$ into $100 \mathrm{~mL}$ of $\mathrm{BaCl}_{2}$ solution $(10 \mathrm{mM})$ with added phytic acid $(1 \mathrm{mM})$ using an automated titration set up by Methrom ${ }^{\circledR}$ Transmittance and free barium in solution were monitored during the experiments with Optrode and a barium ion selective electrode (ISE). pH was kept between 8.0 and 8.2 by addition of $10 \mathrm{mM} \mathrm{NaOH}$. Immediately after the addition of phytic acid, the dosing of sodium sulfate solution $(1 \mathrm{mM})$ at a rate of $60 \mu \mathrm{L} / \mathrm{min}$ started. The solution was stirred at $500 \mathrm{rpm}$ during the experiment. The experiments (3 replicas) were stopped after $\sim 22 \mathrm{hr}$. Samples drawn from the reaction media at the end of the experiment were added to $10 \mathrm{~mL}$ of ethanol to "stop" the precipitation process of $\mathrm{BaSO}_{4}$ and analysed by transmission electron microscopy (TEM). Precipitates were filtered through cellulose-based membranes (pore size $0.1 \mu \mathrm{m}$ ) and characterised ex situ by X-ray diffraction (XRD)

To study later stages of the transformation process, a second set of experiments was performed using a purely inorganic source. Amorphous barium phosphate was synthesised by rapid mixing of $0.1 \mathrm{M} \mathrm{BaCl}_{2}$ and $0.1 \mathrm{M}\left(\mathrm{NH}_{4}\right)_{2} \mathrm{PO}_{4}$ solutions. The precipitates obtained were rapidly filtered through cellulose based membranes $(0.1 \mu \mathrm{m}$ pore diameter $)$ and added to a $25 \mathrm{mM}$ sulfate solution $(10 \mathrm{~mL})$ to simulate barite formation in seawater where an excess of $\mathrm{SO}_{4}{ }^{2-}$ is present ( 3 replicas). The solution was stirred at $500 \mathrm{rpm} .1 \mathrm{~mL}$ aliquots were drawn from the reaction media at different times from $1 \mathrm{~min}$ to $12 \mathrm{hr}$ duration and quenched in ethanol as described above. These samples were analysed by TEM and field emission scanning electron microscopy (FESEM) and X-ray diffraction (XRD), see further details in the Supplementary Information.

\section{Results and Discussion}

During the stepwise addition of sulfate to a barium and phytic acid solution, the monitoring of the transmittance and the free barium revealed that the solution becomes slightly turbid after ca. $3000 \mathrm{~s}$ of sulfate addition (Fig. S-1a,b) and this coincides with a decrease of the free barium in solution (marked points in Fig. S-1b). This is related to the formation of a non-crystalline Ba-P phase, as confirmed by our ex situ analysis (TEM and XRD) that show the absence of single barite particles among the precipitates (Fig. 1). These precipitates are formed mostly by amorphous, globular aggregates of Ba-P nanoparticles (Fig. 1). TEM observations and EDX (Energy Dispersive $X$-ray) microanalysis evidenced the formation of network structures (Fig. 1a) where $\mathrm{Ba}$ and $\mathrm{P}$ are homogeneously distributed, whereas $\mathrm{S}$ was much less abundant and present only in some specific locations (Fig. 1b-e). This indicates that barite did not precipitate directly from the bulk solution but rather as a secondary phase upon transformation of the Ba-P phase. Strikingly, we observed the presence of $\mathrm{C}$ - and $\mathrm{P}$-containing thin films (white arrows in Fig. 1a) that resemble the marine bacterial biofilms which have been suggested to accumulate $\mathrm{Ba}$ at the initial stages of barite formation (Martinez-Ruiz et al., 2018, 2019).

A closer look onto the larger globular structures found in those networks (Fig. 2) shows that indeed, within the amorphous Ba-P matrix and in the areas where sulfur is concentrated, traces of crystalline $\mathrm{BaSO}_{4}$ (Figs. 2, S-2 and S-3) are present. Selected area electron diffraction (SAED) patterns confirmed that barite formed in these locations, as d-spacings corresponding to (011), (210) and (422) were measured. Moreover, high resolution images display lattice fringes exhibiting those $\mathrm{d}$-spacings
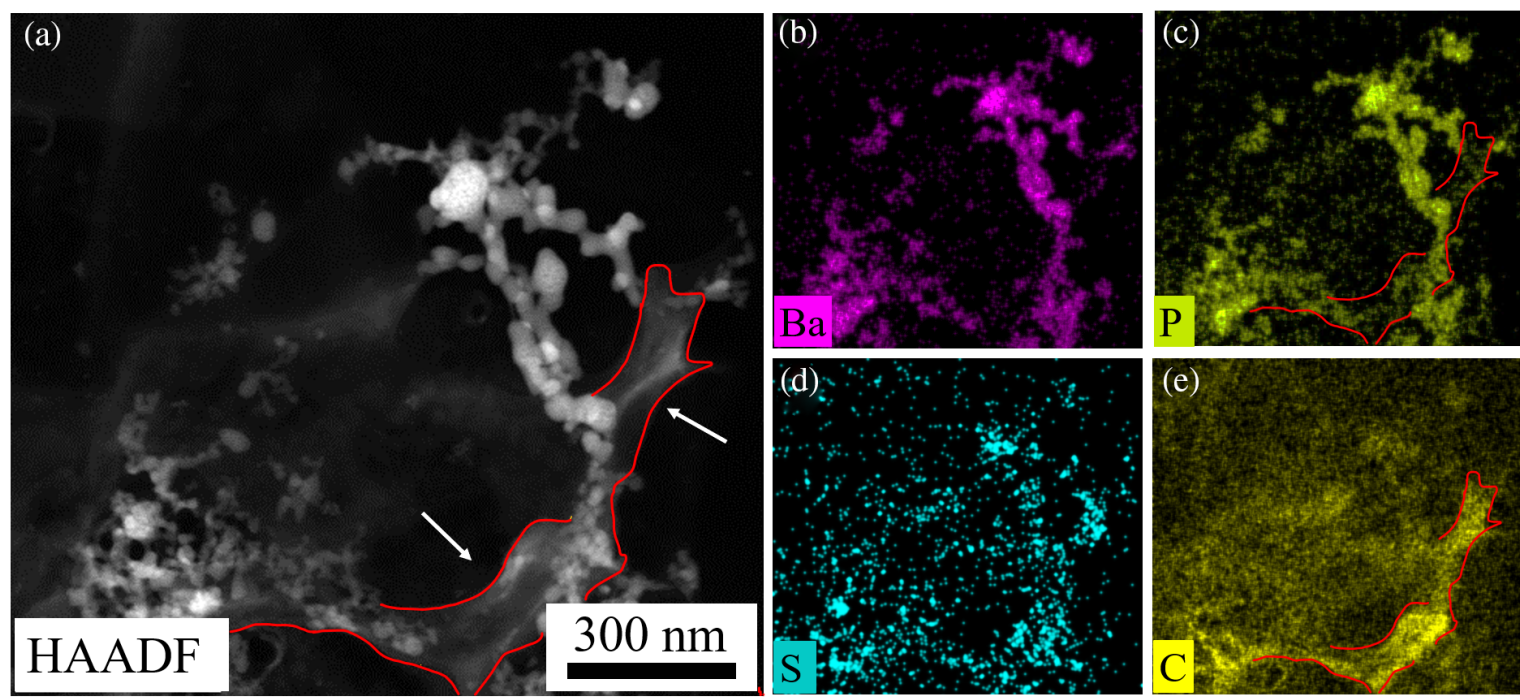

Figure 1 General view of the precipitates formed in the presence of phytic acid. (a) HAADF STEM image showing the obtained structures after experiments. (b) Ba, (c) P, (d) S and (e) C EDX elemental maps of the region depicted in (a). Red line delimits the C-and P-containing film. 

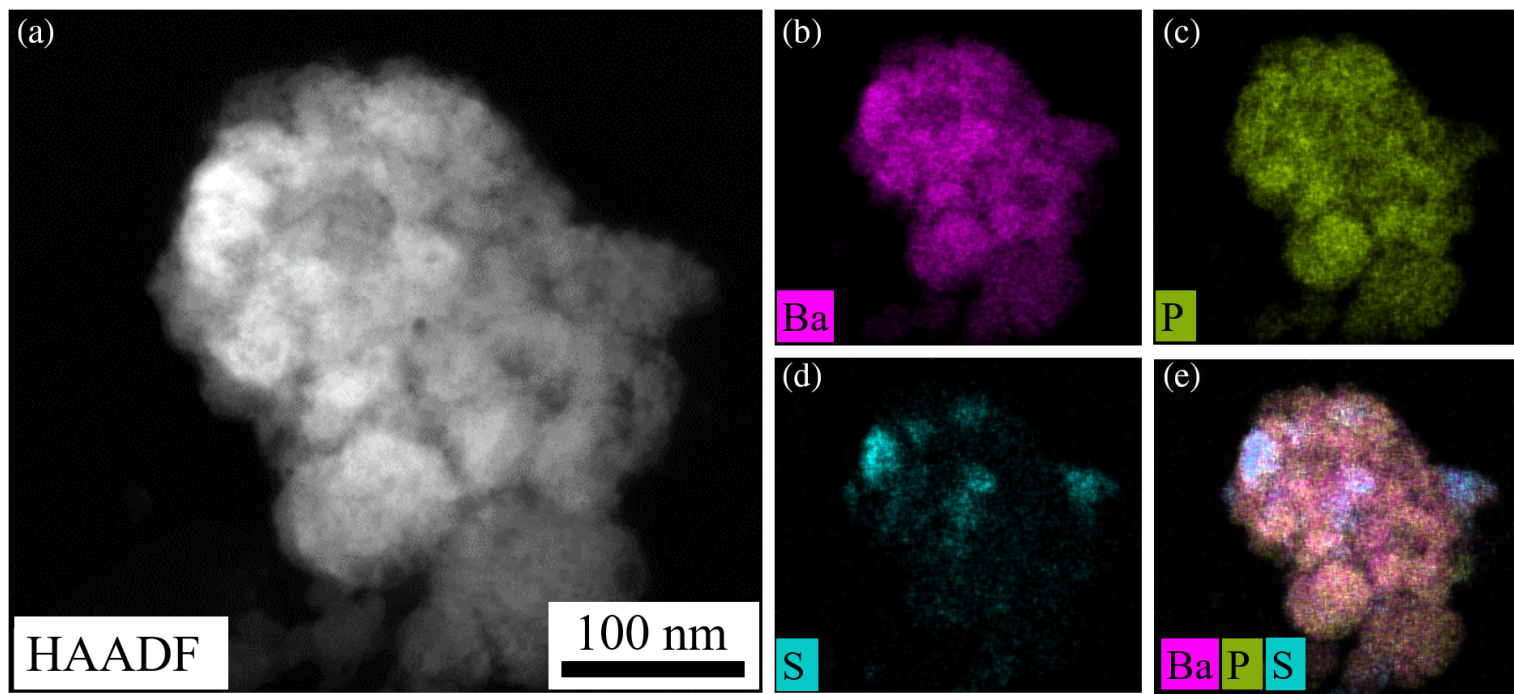

Figure 2 Detailed TEM analysis of globular precipitates formed in the presence of phytic acid. (a) HAADF STEM image showing ill-defined globules. (b) $\mathrm{Ba}$, (c) P, (d) S EDX elemental maps of the region depicted in (a). (e) Overlay of Ba, P and S maps.

(Fig. S-3). This Ba-P amorphous phase formed in the presence of phytic acid is highly porous and does not transform into any crystalline phase for the fluences used in this work and/or after the exposure to environmental conditions (Fig. S-4). Due to the slow rate of transformation of the amorphous Ba-P under the conditions of these titration experiments, large, individual barite particles were not attained during the experimental runs (i.e. after $22 \mathrm{hr}$ from the beginning of the experiment). Thus, a second set of experiments was designed to explore the later stages of the Ba-P transformation into crystalline barite.

In these experiments, barite particles with a size and morphology akin to marine barite were obtained by the rapid reaction of the previously synthesised inorganic Ba-P amorphous phase in a sulfate-bearing solution $(25 \mathrm{mM})$. The starting material consists of aggregates (Fig. S-5a,d) of spherical amorphous nanoparticles (Fig. S-5b) composed of $\mathrm{Ba}, \mathrm{P}$ and $\mathrm{O}$ (Fig. S-5c,e,f). It is worth noting that the particles exhibit high porosity (Fig. S-5b), similar to Ba-P amorphous particles found by previous authors in natural samples (Martinez-Ruiz et al.,
2019), and to those observed here in the first set of experiments. However, this Ba-P amorphous phase was much more labile and metastable, and transformed into Ba-P crystalline phases under environmental conditions (Fig. S-6). This could explain its much faster reactivity in the presence of sulfate, compared to the Ba-P phase obtained from an organic P-source (see above)

After 1 min of contact with the sulfate solution, crystalline barite nanoparticles formed at the expense of the amorphous Ba-P starting material (Fig. 3). The intense diffraction arcs seen in the SAED pattern (inset Fig. 3a) indicate a preferred orientation of the barite nanoparticles in the aggregates growing at expense of the Ba-P spherical particles (Fig. 3a). However, the angular spreading of the reflections shows that the nanocrystallites are not in perfect crystallographic orientation. This orientation becomes much clearer at longer reaction times (see below).

In addition, EDX analysis showed that while barium was distributed all over the particles as expected (Fig. 3b), P (Fig. 3c) and S (Fig. 3d) were much more concentrated on the spherical initial particles and in the aggregates of the elongated nanoparticles,
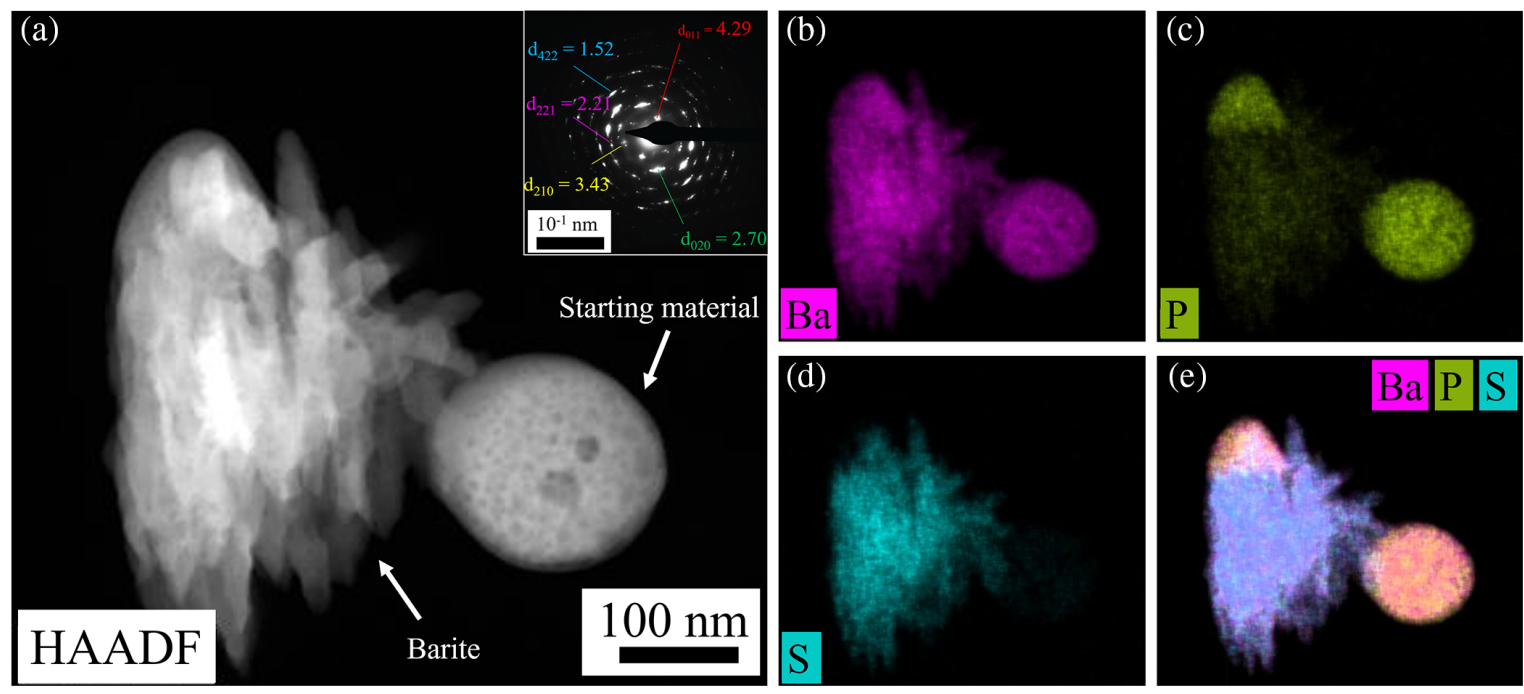

Figure 3 TEM analysis of precipitates formed after 1 min immersion in the sulfate-bearing solution. (a) HAADF image showing the starting Ba-P material and the newly formed, elongate barite structures. (b) Ba, (c) P, (d) S EDX elemental maps of (a). (e) Overlay of Ba, P and S maps. 

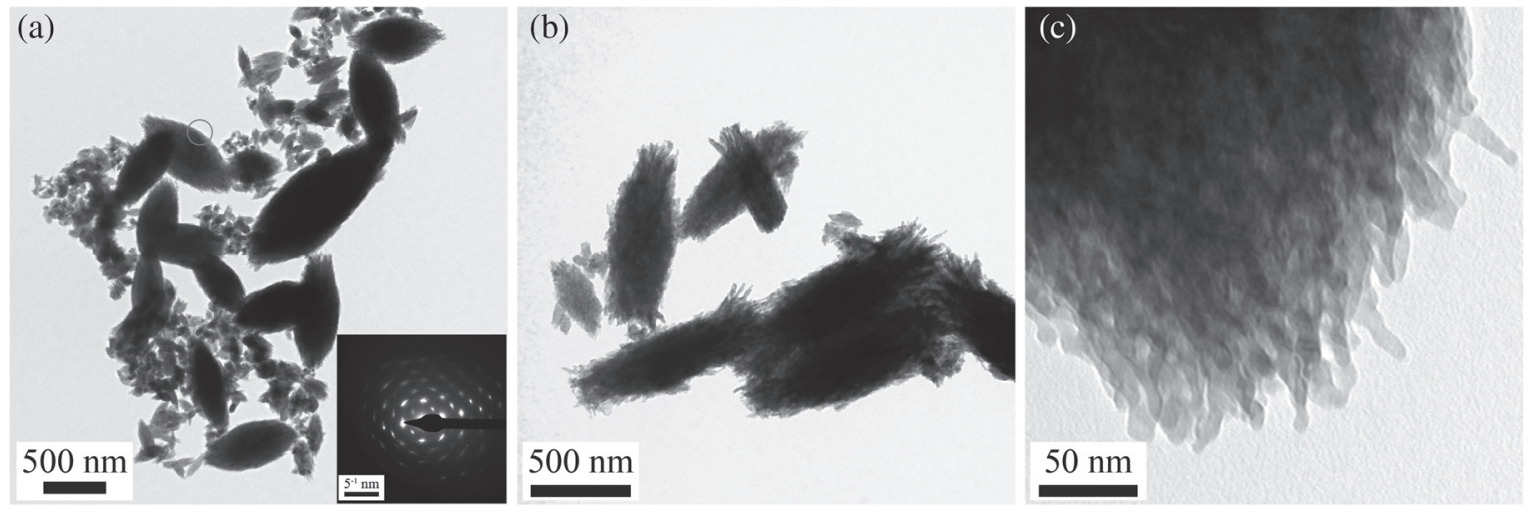

Figure 4 TEM analysis of precipitates formed after (a) 1 and (b) $12 \mathrm{hr}$ immersion in the sulfate solution. Ellipsoidal aggregates of (c) highly oriented barite nanoparticles exhibiting slightly distorted, close to single crystalline electron diffraction pattern (inset in Fig. 4a shows SAED of the area in Fig. 4a marked by the red circle) are observed.

respectively. The starting Ba-P phase and the newly formed barite can be clearly distinguished by the superposition of the $\mathrm{Ba}, \mathrm{P}$, and S elemental maps (Fig. 3e). Samples drawn after 3 (Figs. S-7, S-8) and 5 (Figs. S-9, S-10) minutes of reaction showed similar features, but with slightly larger sizes of the barite particles ( $c a$. 0.2-1 $\mu \mathrm{m})$, which exhibited ellipsoidal or lenticular morphologies (Figs. S-8, S-10).

At longer reaction times ( 1 and $12 \mathrm{hr}$ ) larger barite particles (ca. 0.2-2 $\mu \mathrm{m})$ with well defined ellipsoidal or lenticular morphologies were found (Fig. 4). EDX elemental maps of particles precipitated at both reaction times show that $\mathrm{Ba}, \mathrm{P}$, and $\mathrm{S}$ were homogenously distributed all over the barite particles (Fig. S-11). Traces of $\mathrm{P}$ remained present in the particles after 1 and $12 \mathrm{hr}$ similar to naturally occurring marine barite particles (MartinezRuiz et al., 2019). Interestingly, the SAED pattern (inset from Fig. 4a) obtained in the edges of the particles after $1 \mathrm{hr}$ (red circle in Fig. 4a) depicts a single crystal-like SAED with a slight orientational distortion of the diffraction spots. This indicates a highly self organised superstructure made of elongated nanoparticles subunits (Fig. 4c), defined in the literature as a mesocrystal (Cölfen and Antonietti, 2005; Stawski et al., 2019). It is important to clarify that the term mesocrystal does not relate to a specific mechanism of formation, but rather to the structure of the material.

The results presented above indicate that both organic and inorganic soluble P compounds can form an (solid) amorphous Ba-P phase which serves as a Ba ions reservoir for the further precipitation of barite. The subsequent replacement of phosphate by sulfate ions to yield the final barite particles occurs by the dissolution of the amorphous Ba-P precursor and the subsequent precipitation of barite. We propose that this replacement reaction occurs following an interface coupled dissolutionprecipitation mechanism (ICDP; Putnis, 2002), based on the textural observations of the precipitates formed (Figs. 2, 3). In this mechanism, the dissolution of the precursor Ba-P phase in a sulfate-rich solution releases the barium allowing the sulfate-bearing solution near the dissolving particles to become locally supersaturated with respect to barite. Dissolution is then coupled to barite precipitation, which occurs in close proximity to the surface of the precursor phase. Lenticular morphologies, seen here and in natural samples (Martinez-Ruiz et al., 2019), may result from the preferential orientation of the barite nanoparticles sub-units along the [101] direction. In the light of our results, we suggest that the morphology and mesocrystalline ultra-structure of the barite particles precipitated in our experiments, resembling that of natural marine barite, could result from the replacement reaction of the $\mathrm{Ba}-\mathrm{P}$, which yields the formation of highly oriented nanoparticles assemblies at the interface of the dissolving Ba-P and the solution.

\section{Implications and Conclusions}

As growth characteristics (morphology and size) like those of natural marine barite are expressed in our abiotic barite analogues, our data bring into question the role of the living microorganisms on the nucleation and growth of marine barite, which may be limited to the synthesis or transformation of P-bearing compounds that 'concentrate' barium through the precipitation of a solid Ba-P phase. Moreover, we suggest that the isoorientation of the nanoparticles forming barite crystals and lenticular morphologies are determined by their formation mechanism (precursor amorphous Ba-P phase and its subsequent replacement through an ICDP reaction) rather than by specific organic-crystal interactions either during nucleation or growth. The abundance of P-bearing compounds which can precipitate as $\mathrm{Ba}-\mathrm{P}$ phases that act as precursors for barite formation will certainly increase during periods of microorganism blooms, which supports the link between organic carbon fluxes and barite formation in seawater. These insights regarding the crystallisation mechanism of barite from a Ba-P phase will pave the way for future investigations regarding how these coupled dissolution-precipitation processes, controlled by the local chemistry of the fluid and the element concentration in the amorphous precursor phase rather than by the composition of the bulk seawater, influence the isotopic and trace element signatures of the final barite formed and how this relates to the information extracted from them for the reconstruction of palaeoenvironments.

\section{Acknowledgements}

CRA thanks the SFB 1214 (project A07) funded by the German Research Foundation (DFG) and the Zukunftskolleg from the University of Konstanz. ERA acknowledges funding was provided by the Spanish Government (grant RTI2018-099565B-I00), the Junta de Andalucía (research group RNM-179), and the University of Granada (Unidad Científica de Excelencia UCE-PP2016-05). In addition, we would like to thank the personnel of the "Centro de Instrumentation Científica" (University of Granada) for their support and help with the electron microscopy analysis.

Editor: Liane G. Benning 


\section{Additional Information}

Supplementary Information accompanies this letter at https:// www.geochemicalperspectivesletters.org/article2121.

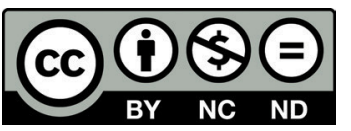

(C) 2021 The Authors. This work is distributed under the Creative Commons Attribution NonCommercial No-Derivatives 4.0 License, which permits unrestricted distribution provided the original author and source are credited. The material may not be adapted (remixed, transformed or built upon) or used for commercial purposes without written permission from the author. Additional information is available at https://www. geochemicalperspectivesletters.org/copyright-and-permissions.

Cite this letter as: Ruiz-Agudo, C., Ibáñez-Velasco, A., RuizAgudo, E. (2021) The role of amorphous P-bearing precursors on barite formation. Geochem. Persp. Let. 18, 32-36.

\section{References}

CÖLfen, H., ANTONIETTI, M. (2005) Mesocrystals, Inorganic Superstructures Made by Highly Parallel Crystallization and Controlled Alignment. Angewandte Chemie International Edition 44, 5576-5591.

Dehairs, F., Chesselet, R., JeDWAB, J. (1980) Discrete suspended particles of barite and the barium cycle in the open ocean. Earth and Planetary Science Letters 49, 528-550.

Dehairs, F., Jaceuet, S., Savoye, N., van Mooy, B.A.S., Buesseler, K.O., Bishop, J.K.B., Lamborg, C.H., Elskens, M., Baeyens, W., Boyd, P.W., CAsciotti, K.L., Monnin, C. (2008) Barium in twilight zone suspended matter as a potential proxy for particulate organic carbon remineralization, Results for the North Pacific. Deep Sea Research Part II, Topical Studies in Oceanography 55, 1673-1683.

Gonzalez-Muñoz, M.T., Martinez-Ruiz, F., Morcillo, F., Martin-Ramos, J.D. PAYTAN A. (2012) Precipitation of barite by marine bacteria: A possible mechanism for marine barite formation. Geology 40, 675-678.

GRIFFITH, E.M., PAYTAN, A. (2012) Barite in the ocean - occurrence, geochemistry and palaeoceanographic applications. Sedimentology 59, 1817-1835.

Jacquet, S.H.M., Dehairs, F., Dumont, I., Becquevort, S., Cavagna, A.J., CARdinaL, D. (2011) Twilight zone organic carbon remineralization in the Polar Front Zone and Subantarctic Zone south of Tasmania. Deep Sea Research Part II, Topical Studies in Oceanography 58, 2222-2234.

KASTNER, M. (1999) Oceanic minerals, their origin, nature of their environment, and significance. Proceedings of the National Academy of Sciences of the United States of America 96, 3380-3387.

Martinez-Ruiz, F., Kastner, M., Gallego-Torres, D., Rodrigo-Gámiz, M., NietoMoreno, V., Ortega-Huertas, M. (2015) Paleoclimate and paleoceanography over the past 20,000 yr in the Mediterranean Sea Basins as indicated by sediment elemental proxies. Quaternary Science Reviews 107, 25-46.

Martinez-Ruiz, F., Jroundi, F., Paytan, A., Guerra-TschuschKe, I., Abad, M.D.M GonZÁLeZ-Muñoz, M.T. (2018) Barium bioaccumulation by bacterial biofilms and implications for Ba cycling and use of Ba proxies. Nature Communications 9, 1619

Martinez-Ruzz, F., Paytan, A., Gonzalez-Muñoz, M.T., Jroundi, F., Abad, M.M. LAm, P.J., Bishop, J.K.B., HORner, T.J, MORTON, P.L, Kastner, M. (2019) Barite formation in the ocean, Origin of amorphous and crystalline precipitates. Chemical Geology 511, 441-451.

Monnin, C., Jeandel, C., Cattaldo, T., Dehairs, F. (1999) The marine barite saturation state of the world's oceans. Marine Chemistry 65, 253-261.

Paytan, A., Griffith, E.M. (2007) Marine barite: Recorder of variations in ocean export productivity. Deep Sea Research Part II, Topical Studies in Oceanography 54, 687-705.

Paytan, A., McLaughin, K. (2007) The Oceanic Phosphorus Cycle. Chemical Reviews 107, 563-576.

Paytan, A. Kastner, M., Chavez, F.P. (1996) Glacial to Interglacial Fluctuations in Productivity in the Equatorial Pacific as Indicated by Marine Barite. Science 274, 1355-1357.

Planchon, F., Cavagna, A.-J., Cardinal, D., André, L., Dehairs, F. (2013) Late summer particulate organic carbon export and twilight zone remineralisation in the Atlantic sector of the Southern Ocean. Biogeosciences 10, $803-820$.
PutNis, A. (2002) Mineral replacement reactions, from macroscopic observations to microscopic mechanisms. Mineralogical Magazine 66, 689-708.

Schoepfer, S.D., Shen, J., Wei, H., Tyson, R.V., Ingall, E., Algeo, T.J. (2015) Total organic carbon, organic phosphorus, and biogenic barium fluxes as proxies for paleomarine productivity. Earth-Science Reviews 149, 23-52.

Stawski, T.M., Freeman, H. M., van Driessche, A.E.S., Hövelmann, J., Besselink, R., WirTH, R., BEnNing, L.G. (2019) Particle-Mediated Nucleation Pathways Are Imprinted in the Internal Structure of Calcium Sulphate Single Crystals. Crystal Growth \& Design 19, 3714-3721. 